\title{
An Improved Mathematical Model of Cutting Temperature in End Milling Al7050 Based on the Influence of Tool Geometry Parameters and Milling Parameters
}

\author{
Junhao Ji, Qi Yang $\mathbb{D}^{D}$, Peng Chen, Kaijie Lu, and Yuhan Wu \\ College of Mechanical and Electrical Engineering, Wenzhou University, Wenzhou 325035, China \\ Correspondence should be addressed to Qi Yang; wdyangqi@163.com
}

Received 16 May 2021; Revised 4 June 2021; Accepted 12 June 2021; Published 21 June 2021

Academic Editor: Krzysztof Kecik

Copyright (c) 2021 Junhao Ji et al. This is an open access article distributed under the Creative Commons Attribution License, which permits unrestricted use, distribution, and reproduction in any medium, provided the original work is properly cited.

\begin{abstract}
Excessively high temperature during milling will shorten the life of the milling tools, reduce the surface quality of the workpiece, and increase production costs. In this paper, a novel cutting temperature prediction model for milling Al7050 is proposed, which considers both tool geometry parameters and milling parameters. The aim is to adjust the milling conditions in advance according to the predicted temperature, thereby prolonging the tool life and improving the machining quality. Through single-factor experiments, it is found that there is a polynomial relationship between tool geometric parameters and cutting temperature. Based on the empirical formula of cutting temperature, an improved mathematical model of cutting temperature is proposed. In this model, eight variables including tool geometry parameters and milling parameters are considered. The coefficients of the mathematical model are determined by the cyclic fitting method. The simulation data and experimental data show that compared with the temperature prediction model considering only milling parameters, this model has better prediction accuracy. This idea can also be used to establish the cutting temperature prediction model of other materials.
\end{abstract}

\section{Introduction}

Widely used in high-speed train, aerospace, aircraft, and other manufacturing industries, milling plays an important role in manufacturing, mainly due to its advantages in high production efficiency and excellent surface processing quality, which leads to lower production costs and higher economic efficiency in mass production. In the milling process, cutting force, cutting temperature, cutter displacements, etc., which are affected by many factors, are directly related to the final machining quality. It is very important to model them and predict the possible situation $[1,2]$.

The highest cutting temperature produced during milling is an important analytical and control parameter, because excessive high temperature not only accelerates tool wear and shortens the tool life, but also impairs the surface quality of the workpiece. Detailed study on the prediction of cutting temperature would facilitate the cutting condition controlled during milling, thereby preventing the tool from working at excessively high temperature. Currently, the prediction methods of cutting temperature can be summarized into the following four types: empirical equation, analytical method, numerical method, and neural network method $[3,4]$.

Kadirgama et al. [5] established a first-order tool temperature mathematical model for determining tool temperature by using the response surface method. Yi-jian et al. [6] developed a nonlinear curve using particle swarm optimization to determine the cutting temperature. Bai et al. [7] detected the change of cutting temperature during high-speed milling of Al7050-T7451 aluminum alloy and established an empirical equation of cutting temperature through experimental analysis. Theoretical prediction yielded by this equation match well with the measured temperature. Findes et al. [8] studied the influences of cutting speed, feed rate, and cutting depth on cutting force and cutting temperature when machining AISIH11 steel with composite ceramic tools. It has 
been found that the cutting speed affects the temperature in the cutting zone more significantly than the cutting depth and feed rate do. Richardson et al. [9] established a temperature prediction model in the dry milling process of aerospace aluminum alloys and found that higher cutting speed and feed rate can reduce the temperature rise of the workpiece. Toh et al. [10] compared the surface temperature of the chip of hardened steel during down milling and up milling by infrared technology. Spânu and Iliescu [11] used a full-factor experimental design method to develop a mathematical model of cutting zone temperature during the milling of GFRP materials via polynomial regression technique. Cutting speed, feed rate, and cutting depth are changed during the experiment and the corresponding temperatures are recorded by a thermal camera. Chien et al. [12] used the AdvantEdge software to simulate ball end milling of Inconel 718 with a coated carbide tool. With the cutting speed, feed rate, and axial cutting depth taken into consideration, they designed a three-factor and three-level experiment using Box-Behnken method and developed a linear polynomial model of the maximum temperature of the tool using multiple linear regression. Abhang and Hameedullah [13] used the tool-work thermocouple technology and conducted an experimental study on the average temperature of the chip-tool contact surface. They believe that factors such as cutting speed, feed rate, depth of cut, and blunt radius have a certain impact on the chip-tool contact surface temperature during EN-31 steel alloy turning. Based on this conclusion, the first- and secondorder empirical models have been established. Saglam et al. [14] studied the influencing factors of cutting force component and tool tip temperature and found that the rake angle was effective on all cutting force components, while the cutting speed was effective on the tool tip temperature. Santhanakrishnan et al. [15] studied the influences of the blunt radius, rake angle, cutting depth, feed rate, and cutting speed on the temperature rise during the milling of the Al6351 with high-speed steel. Sheng et al. [16] studied the influences of cutting speed and tool wear rate on cutting temperature in milling. The authors obtained an empirical equations of cutting temperature, involving feed rate, axial cutting depth, cutting speed, and radial cutting depth, via an orthogonal regression test. Kaushik et al. [17] studied the effects of helix angle, rake angle, cutting speed, feed rate, and axial cutting depth on cutting temperature when milling Al7068 with highspeed steel and milling and developed a multivariate secondorder mathematical model. Rana and Kumar [18] developed a mathematical model of the cutting temperature when using a tungsten carbide tool to turn EN19 steel by central composite design method. Using a central combination design method, Zeelanbasha et al. [19] designed the cutting experiment of cutting Al6006-T6 with high-speed steel end milling and established a second-order mathematical model of dependency of cutting temperature on spindle speed, feed rate, axial cutting depth, radial depth of cut, and rake angle. Zheng et al. [20] adopted the method of combining simulation and experimental verification to establish the $2 \mathrm{D}$ milling simulation model, studied the influence of milling parameters (feed rate, milling depth, spindle speed, milling width, and milling depth) on milling force and milling temperature during the milling process of 7075 aluminum alloy, then carried out milling parameter optimization. Ping et al. [21] studied the influences of milling parameters and tool geometric parameters on milling force and milling temperature through single-factor experiment.

In the analytical prediction of cutting temperature, Aneiro et al. [22] conducted experiments on hardened steel with multilayer coated carbide tools and studied the influencing factors of tool temperature, tool wear, cutting force, and surface roughness. Under conditions of fixed cutting speed and metal removal rate, Cui et al. [23] studied dependencies of the average instantaneous temperature of the tool on the radial depth of cut and the feed rate when the AISI H13 tool steel was face-milled with an uncoated cemented carbide tool. Zhou [24] proposed an analytical model for predicting workpiece temperature in a torus end mill with 4-axis milling and verified the validity of the model.

There are mainly two methods for numerical studies on turning and milling temperature: the finite element method (FEM) and the finite difference method (FDM). Lin et al. [25] proposed analytical model of workpiece temperature using the finite difference method (FDM), which takes into account the complex tool geometric and the effect of friction on the flank of the tool on the temperature rise. Sreeramulu et al. [26] used FEM software (Deform-3D) to simulate three-dimensional tilt cutting operations and studied the influences of cutting speed, feed rate, and cutting depth on cutting temperature. Lacalle et al. [27] performed finite element simulation of dry milling of forged aluminum alloys. The authors found that the cutting temperature rises as the cutting speed and inclination angle increase.

In neural network prediction, Rai et al. [28] established a new temperature prediction model of shear plane during end milling through a feed-forward back propagation neural network. Korkut et al. [29] predicted the temperature of the cutting-edge contact interface of the tool by regression analysis and artificial neural network. Considering the cutting speed, feed rate, and the cutting depth, Masoudi et al. [30] used artificial neural network (ANN) and adaptive neurofuzzy inference system (ANFIS) to predict cutting temperature.

The above researches on cutting temperature prompt the development of the study on cutting temperature, but most of them focus on the relationship between cutting parameters (less than five) and cutting temperature; it is not clear how the tool geometric parameters affect the cutting temperature. The model proposed in this paper considers eight parameters including milling parameters and can better reflect the variation of cutting temperature during milling.

\section{Experiment Methodology}

2.1. Workpiece Material, Tool Material, and Tool Geometry Parameters. This study uses aluminum alloy 7050 as the workpiece material. Aluminum alloy 7050 has been widely used in aerospace, automotive industry, and lightweight construction due to its high strength, high toughness, and excellent resistance to stress corrosion. 
Ultrafine grained carbide materials, widely used in aviation enterprises, are selected as tool materials. The cemented carbide tool is one of the main cutting tools for cutting aluminum alloys because of its sharp cutting edge, good antiflaking performance, and good wear resistance.

During the milling process, tool geometry parameters play an important role. They should be taken into consideration when choosing the cutter, such as diameter, blunt radius, helix angle, rake angle, and relief angle. In the singlefactor experiment, the nonvariable tool geometry parameters are set as follows: the milling cutter diameter is $16 \mathrm{~mm}$, the blunt radius is $0.01 \mathrm{~mm}$, the helix angle is $30^{\circ}$, the rake angle is $15^{\circ}$, and the relief angle is $8^{\circ}$.

2.2. Finite Element Milling Model. During the milling process, the cutting part can be treated as turning. The plane perpendicular to the axial direction of the tool is selected as the reference place, as shown in Figure 1(a). In Figure 1(b), keeping the cutting length constant, the undeformed chip thickness varied with the cutting position. So, the milling can be completely converted to orthogonal turning with varying undeformed chip thickness. To make the cutting mechanism easier and more intuitive, the cutting process can be simplified to $2 \mathrm{D}$ orthogonal cutting. The projections of the rake face and flank surface are simplified to straight lines and a nose arc. In general, due to the influence of helix angle, milling is an oblique cutting process. The active cutting edge and the cutting speed direction are not perpendicular to each other, which results in changes in the rake angle and the relief angle. In the $2 \mathrm{D}$ milling simulation process, the equivalent angle of the tool is calculated by the following formula [31]:

$$
\left\{\begin{array}{l}
\sin \gamma_{o e}=\sin \lambda_{s} \sin \psi_{A}+\cos \lambda_{s} \cos \psi_{A} \sin \gamma_{n}, \\
\cos \alpha_{o e}=\sin \lambda_{s} \sin \psi_{A}+\cos \lambda_{s} \cos \psi_{A} \cos \alpha_{n},
\end{array}\right.
$$

where $r_{o e}$ is the turning tool's equivalent rake angle, $\alpha_{o e}$ is the turning tool's equivalent relief angle, $\psi_{A}$ is the flow chip angle, $\lambda_{s}$ is the shear angle, $\gamma_{n}$ is the rake angle, and $\alpha_{n}$ is the relief angle.

\section{Influence of Tool Geometry on Cutting Temperature}

The single-factor simulations of tool geometry parameters were carried out to study the relationship between the changes of tool geometry parameters and the corresponding cutting temperature when machining aluminum alloy 7050 . The milling parameters are as follows: spindle speed is $15000 \mathrm{r} / \mathrm{min}$, feed per tooth is $0.15 \mathrm{~mm}$, the cutting depth is $1.5 \mathrm{~mm}$, and the cutting width is $1.5 \mathrm{~mm}$.

3.1. Tool Diameter. The parameter range of the tool diameter is set to $6-24 \mathrm{~mm}$ with increments of $2 \mathrm{~mm}$. The relationship between the cutting temperature and the diameter of the milling cutter is shown in Figure 2. The standard deviation of the data in Figure 2 is 37.80, which means that the tool diameter has a great influence on the cutting temperature.
Figure 2 shows that the cutting temperature gradually increases as the tool diameter increases. Polynomial fitting $\left(T=-0.2487 x_{d}{ }^{2}+13.911 x_{d}+209.99\right)$ shows higher accuracy for the relationship between tool diameter and cutting temperature among fitting ways like exponential, linear, logarithm fittings, with the fitting accuracy $R^{2}$ of 0.9975 (Table 1). Based on the above analysis, it can be concluded that selecting a smaller tool diameter is advantageous for reducing the cutting temperature. Nevertheless, it should be noted that the smaller tool diameter, the greater the cutting force, so a trade-off must be made between the cutting force and cutting temperature.

3.2. Blunt Radius. The parameter range of the blunt radius is set to $2.5-25 \mu \mathrm{m}$ with increments of $2.5 \mu \mathrm{m}$. The relationship between the blunt radius and the cutting temperature is shown in Figure 3. The standard deviation of the data in Figure 3 is 7.72 . The cutting temperature fluctuates with the change of blunt radius. Figure 3 demonstrates that as the blunt radius increases, the cutting temperature tends to increase. Polynomial fitting $\left(T=-0.0041 x_{r}^{2}+1.1545 x_{r}+349.89\right)$ shows higher accuracy for the relationship between blunt radius and cutting temperature among fitting ways like exponential, linear, logarithm fittings, with the fitting accuracy $R^{2}$ of 0.9975 (Table 1). In the actual cutting process of aluminum alloy, the cutting edge of the cemented carbide tool is generally not rounded, which also conforms to the rule of the blunt radius and the cutting temperature.

3.3. Helix Angle. The parameter range of the helix angle is set to $12-40^{\circ}$ with increments of $4^{\circ}$, and the relationship between the helix angle and the cutting temperature is shown in Figure 4. The standard deviation of the data in Figure 4 is 12.61. The cutting temperature fluctuates with the change of helix angle. Figure 4 shows a nonlinear relationship between the cutting temperature and the helix angle; the cutting temperature decreases with the increase of the helix angle of the milling cutter. Polynomial fitting $\left(T=-0.036 x_{l}^{2}+0.5372 x_{l}+382.92\right)$ shows higher accuracy for the relationship between tool helix angle and cutting temperature among fitting ways like exponential, linear, and logarithm fittings, with the fitting accuracy $R^{2}$ of 0.9821 (Table 1). According to Figure 4, it can be seen that when milling aluminum alloy 7050 at high speed, a larger helix angle should be selected, and a larger helix angle is often used in actual production.

3.4. Rake Angle. The single-factor analysis parameter of the tool rake angle is set to $6-26^{\circ}$ with an increment of $2^{\circ}$, and the variation of cutting temperature with tool rake angle is shown in Figure 5. The standard deviation of the data in Figure 5 is 11.33 . The cutting temperature fluctuates with the change of rake angle. Figure 5 shows that there is a decreasing relationship between them. The reason is that the shear angle decreases with the increase of rake angle, and the plastic deformation of metal and the friction of rake face 


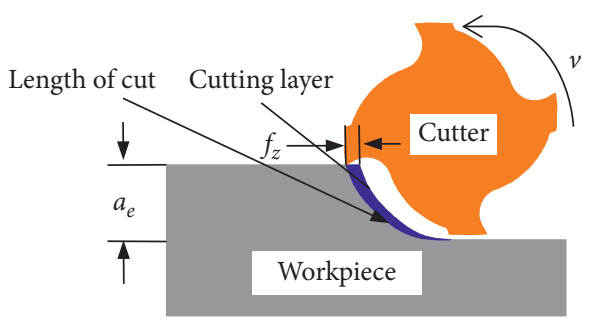

(a)

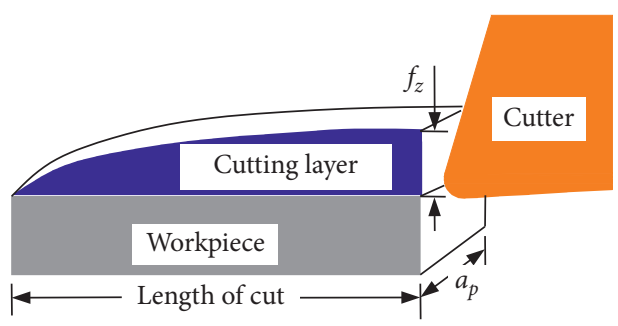

(b)

FIGURE 1: Milling model. (a) Axial cross section of 3D model. (b) 2D simplified model.

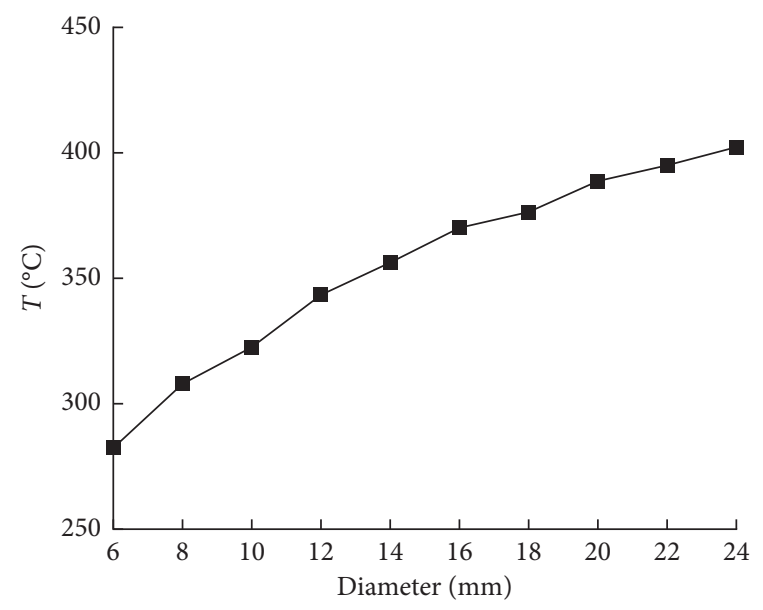

Figure 2: Single-factor experiment of tool diameter.

TABLE 1: Fitting accuracy of each method.

\begin{tabular}{lcccc}
\hline & \multicolumn{4}{c}{ Fitting accuracy } \\
& Polynomial & Exponential & Linear & Logarithm \\
\hline Tool diameter & 0.9975 & 0.9405 & 0.969 & 0.9879 \\
Blunt radius & 0.938 & 0.9376 & 0.934 & 0.855 \\
Helix angle & 0.9821 & 0.9347 & 0.934 & 0.8404 \\
Rake angle & 0.9545 & 0.9446 & 0.951 & 0.8946 \\
\hline
\end{tabular}

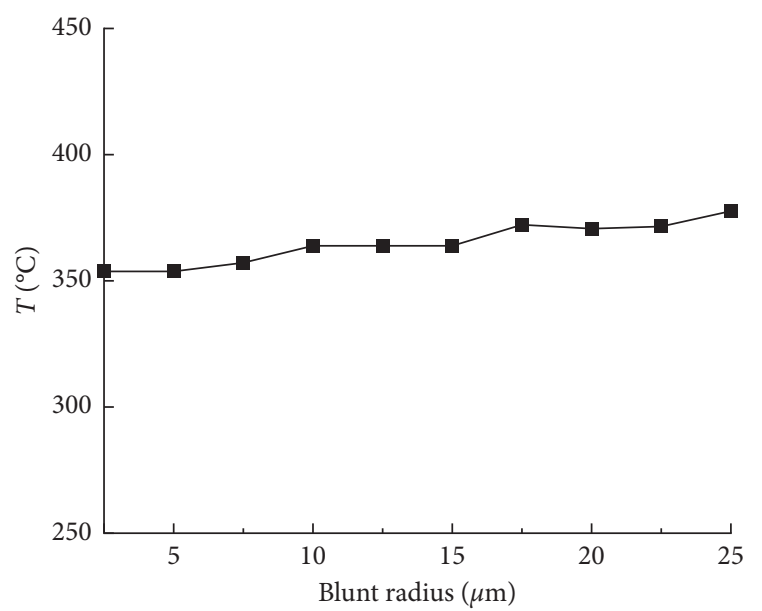

FIGURE 3: Single-factor experiment of blunt radius.

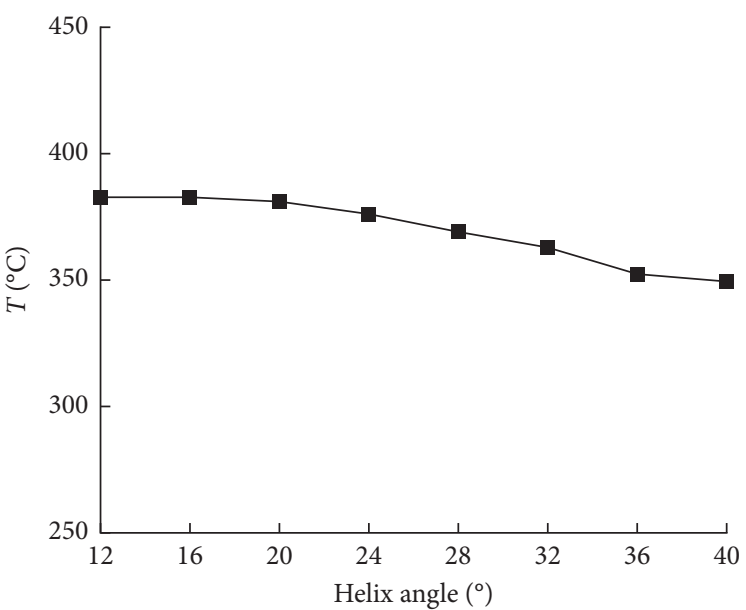

Figure 4: Single-factor experiment of the helix angle.

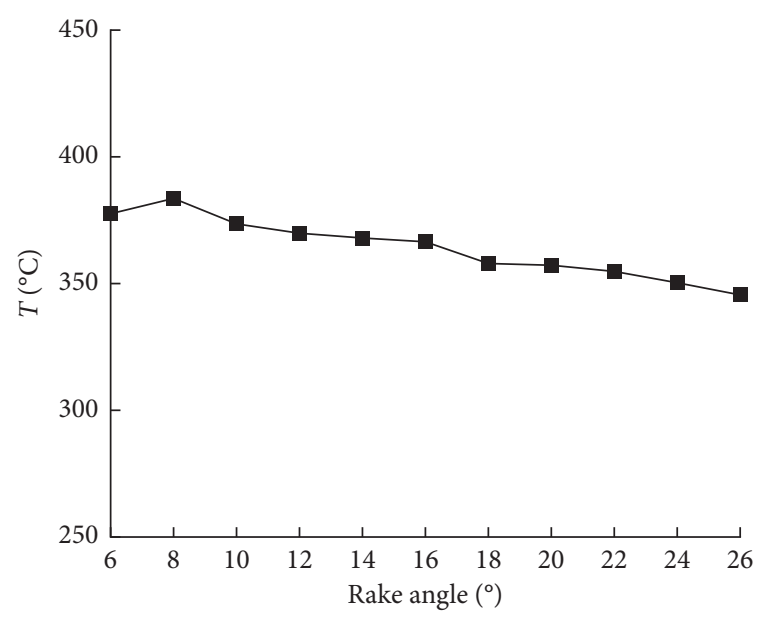

FIGURE 5: Single-factor experiment of the rake angle.

decrease, which leads to the decrease of cutting temperature. Polynomial fitting $\left(T=-0.0123 x_{q}^{2}-1.3561 x_{q}+389.38\right)$ shows higher accuracy for the relationship between tool rake angle and cutting temperature among fitting ways like exponential, linear, and logarithm fittings, with the fitting accuracy $R^{2}$ of 0.9545 (Table 1). Ensuring sufficient strength of the milling cutter blade, a large rake angle helps to reduce 
the cutting temperature. Generally, the cemented carbide tools selected have large rake angles $\left(12^{\circ}-20^{\circ}\right)$, due to the low hardness of aluminum alloys.

3.5. Relief Angle. The parameter range of the tool relief angle is set to $2^{\circ}-16^{\circ}$ with increments of $2^{\circ}$. The relationship between the tool relief angle and the cutting temperature is shown in Figure 6. The standard deviation of the data in Figure 6 is 2.17, which means that the data fluctuates slightly. As the relief angle increases, the cutting temperature remains almost unchanged, which is in line with the rule that the highest cutting temperature occurs where the chip meets the rake face of the tool. Therefore, the effect of the relief angle on the cutting temperature can be ignored.

\section{An Improved Mathematical Model of Cutting Temperature}

4.1. Empirical Equation of Cutting Temperature. According to the metal cutting principle, the mathematic relation between the cutting temperature and the milling parameters is governed by an exponential equation. The general form of the cutting temperature empirical equation is [32]

$$
T=C v^{i} f_{z}^{j} a_{p}^{m} a_{e}^{n},
$$

where $v$ is the cutting speed, $f_{z}$ is the feed per tooth, $a_{p}$ is the cutting depth, $a_{e}$ is the cutting width, $i, j, m$, and $n$ are the exponential coefficients corresponding to each parameter, and $C$ depends on the workpiece material and cutting condition.

To fit the empirical model, a milling parameter orthogonal experiment of four factors and four levels was carried out. In the experiment, the blunt radius is $0.01 \mathrm{~mm}$, the helix is $30^{\circ}$, the rake angle is $15^{\circ}$, and the relief angle is $8^{\circ}$. Table 2 shows the simulation results under different milling parameters.

By fitting the above simulation results, the empirical model of cutting temperature for cemented carbide tool milling aluminum alloy 7050 is obtained:

$$
T=491.1256 v^{0.0093} f_{z}^{0.2709} a_{p}^{-0.0027} a_{e}^{0.1508} .
$$

4.2. Improved Model of Cutting Temperature. According to the above single-factor test results and the relationship obtained by fitting, we can infer that there is a nonlinear relationship of polynomial between the cutting temperature and tool geometry parameters during milling. Based on the empirical equation of cutting temperature, the parameters of the four tool geometry parameters and the cutting temperature empirical model are combined to obtain the following relationship:

$$
\begin{aligned}
T= & \left(k_{0}+k_{1} x_{d}+k_{2} x_{r}+k_{3} x_{l}+k_{4} x_{q}+k_{5} x_{d}^{2}+k_{6} x_{r}^{2}\right. \\
& \left.+k_{7} x_{l}^{2}+k_{8} x_{q}^{2}\right) v^{k_{9}} f_{z}^{k 10} a_{p}^{k 11} a_{e}^{k 12},
\end{aligned}
$$

where $x_{d}$ is the tool diameter, $x_{r}$ is the blunt radius, $x_{l}$ is the helix angle, $x_{q}$ is the rake angle, $k_{0}$ is a constant, and $k_{i}(i=1$,

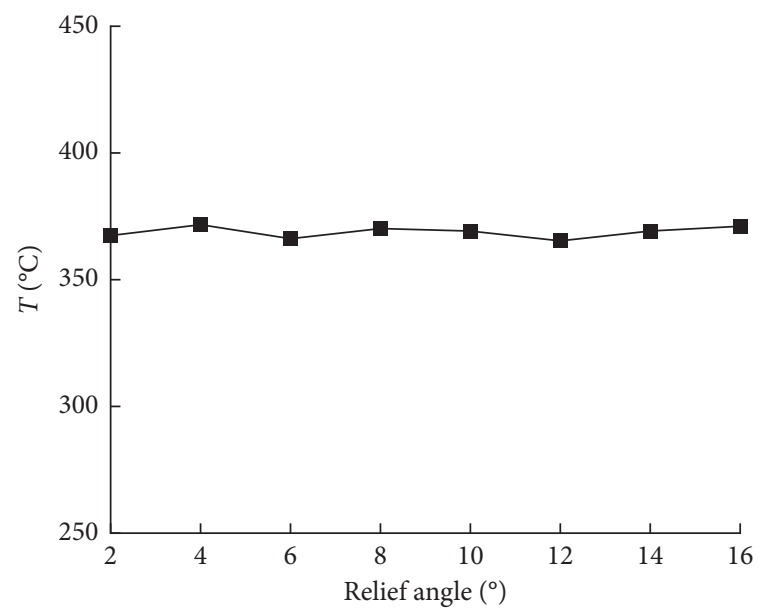

FIgURE 6: Single-factor experiment of the relief angle.

TABLE 2: Orthogonal test of milling parameters.

\begin{tabular}{lccccc}
\hline No. & $v\left(\mathrm{~mm} * s^{-1}\right)$ & $f_{z}\left(\mathrm{~mm} * z^{-1}\right)$ & $a_{p}(\mathrm{~mm})$ & $a_{e}(\mathrm{~mm})$ & $T\left({ }^{\circ} \mathrm{C}\right)$ \\
\hline 1 & 250 & 0.05 & 1.5 & 1.5 & 189.5 \\
2 & 250 & 0.1 & 3 & 3 & 246.0 \\
3 & 250 & 0.15 & 4.5 & 4.5 & 287.2 \\
4 & 250 & 0.2 & 6 & 6 & 321.8 \\
5 & 500 & 0.05 & 3 & 4.5 & 281.3 \\
6 & 500 & 0.1 & 1.5 & 6 & 352.5 \\
7 & 500 & 0.15 & 6 & 1.5 & 319.4 \\
8 & 500 & 0.2 & 4.5 & 3 & 381.5 \\
9 & 750 & 0.05 & 4.5 & 6 & 327.6 \\
10 & 750 & 0.1 & 6 & 4.5 & 384.0 \\
11 & 750 & 0.15 & 1.5 & 3 & 401.0 \\
12 & 750 & 0.2 & 3 & 1.5 & 391.8 \\
13 & 1000 & 0.05 & 6 & 3 & 335.0 \\
14 & 1000 & 0.1 & 4.5 & 1.5 & 360.2 \\
15 & 1000 & 0.15 & 3 & 6 & 489.7 \\
16 & 1000 & 0.2 & 1.5 & 4.5 & 336.4 \\
\hline
\end{tabular}

$2,3, \ldots, 12)$ is the coefficient corresponding to each parameter.

To fit the improved model, a tool geometry parameter orthogonal experiment of four factors and four levels was carried out. The milling parameters are as follows: the cutting speed is $750 \mathrm{~m} / \mathrm{min}$, the feed per tooth is $0.1 \mathrm{~mm}$, the axial depth is $0.15 \mathrm{~mm}$, and the radial depth is $0.15 \mathrm{~mm}$; the geometry parameters and simulation results of the end milling are shown in Table 3.

Based on the simulation results shown in Table 2, the following relationship is obtained via cycle fitting, the process of which is shown in the flowchart in Figure 7:

$$
\begin{aligned}
T= & \left(208.787-2.2025 x_{d}-485.7525 x_{r}-0.2387 x_{l}\right. \\
& \left.-2.8342 x_{q}+0.0407 x_{d}^{2}+24163 x_{r}^{2}-0.0087 x_{l}^{2}-0.0777 x_{q}^{2}\right) \\
& \cdot v^{0.1864} f_{z}^{0.2104} a_{p}^{0.0046} a_{e}^{0.08} .
\end{aligned}
$$

The tool diameter, blunt radius, helix angle, and the rake angle of equation (6) do not completely conform to the 
TABLE 3: Orthogonal test of tool geometry parameters.

\begin{tabular}{|c|c|c|c|c|c|}
\hline No. & $x_{d}(\mathrm{~mm})$ & $x_{r}(\mathrm{~mm})$ & $x_{1}\left({ }^{\circ}\right)$ & $x_{q}\left({ }^{\circ}\right)$ & $T\left({ }^{\circ} \mathrm{C}\right)$ \\
\hline 1 & 8 & 0.005 & 20 & 5 & 304.9 \\
\hline 2 & 8 & 0.01 & 25 & 10 & 297.1 \\
\hline 3 & 8 & 0.015 & 30 & 15 & 264.4 \\
\hline 4 & 8 & 0.02 & 35 & 20 & 274.6 \\
\hline 5 & 12 & 0.005 & 25 & 15 & 306.1 \\
\hline 6 & 12 & 0.01 & 20 & 20 & 309.5 \\
\hline 7 & 12 & 0.015 & 35 & 5 & 297.2 \\
\hline 8 & 12 & 0.02 & 30 & 10 & 301.9 \\
\hline 9 & 16 & 0.005 & 30 & 20 & 313.8 \\
\hline 10 & 16 & 0.01 & 35 & 15 & 318.7 \\
\hline 11 & 16 & 0.015 & 20 & 10 & 348.3 \\
\hline 12 & 16 & 0.02 & 25 & 5 & 375.0 \\
\hline 13 & 20 & 0.005 & 35 & 10 & 338.4 \\
\hline 14 & 20 & 0.01 & 30 & 5 & 368.4 \\
\hline 15 & 20 & 0.015 & 25 & 20 & 326.4 \\
\hline 16 & 20 & 0.02 & 20 & 15 & 341.1 \\
\hline
\end{tabular}

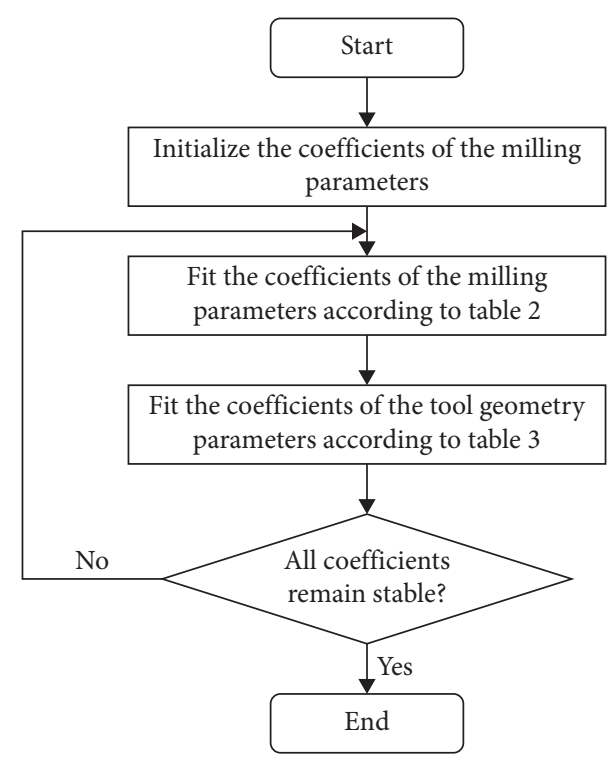

Figure 7: Flowchart of cycle fitting.

TABLE 4: Simulation conditions and results.

\begin{tabular}{|c|c|c|c|c|c|c|c|c|c|}
\hline No. & $x_{d}(\mathrm{~mm})$ & $x_{r}(\mathrm{~mm})$ & $x_{1}\left({ }^{\circ}\right)$ & $x_{q}\left({ }^{\circ}\right)$ & $v\left(\mathrm{~mm} * \mathrm{~s}^{-1}\right)$ & $f_{z}\left(\mathrm{~mm} * z^{-1}\right)$ & $a_{p}(\mathrm{~mm})$ & $a_{e}(\mathrm{~mm})$ & $T\left({ }^{\circ} \mathrm{C}\right)$ \\
\hline 1 & 12 & 0.01 & 30 & 15 & 400 & 0.1 & 4 & 4 & 306.6 \\
\hline 2 & 16 & 0.015 & 35 & 20 & 600 & 0.15 & 6 & 6 & 384.1 \\
\hline 3 & 8 & 0.015 & 35 & 10 & 500 & 0.2 & 3 & 2 & 361.2 \\
\hline \multirow[t]{2}{*}{4} & 10 & 0.01 & 30 & 15 & 400 & 0.1 & 3 & 3 & 303.2 \\
\hline & 18 & 0.008 & 25 & 16 & 900 & 0.08 & 6 & 2 & 331.5 \\
\hline
\end{tabular}

single-factor rule in the range of values. The reason may lie in the insufficient number of orthogonal experiments, in which only a few typical points are selected for the test and results in the concealing of the rule. Therefore, we can make the equation conform to the single-factor rule by limiting the range of the parameter coefficients, and the following equation is obtained:

$$
\begin{aligned}
T= & \left(308.486+2.973 x_{d}-495.315 x_{r}-0.306 x_{l}-2.915 x_{q}\right. \\
& \left.+0.0208+20159 x_{r}^{2}-0.001 x_{l}^{2}-0.0701 x_{q}^{2}\right) \\
& \cdot v^{0.777} f_{z}^{0.2428} a_{p}^{0.005} a_{e}^{0.0499} .
\end{aligned}
$$




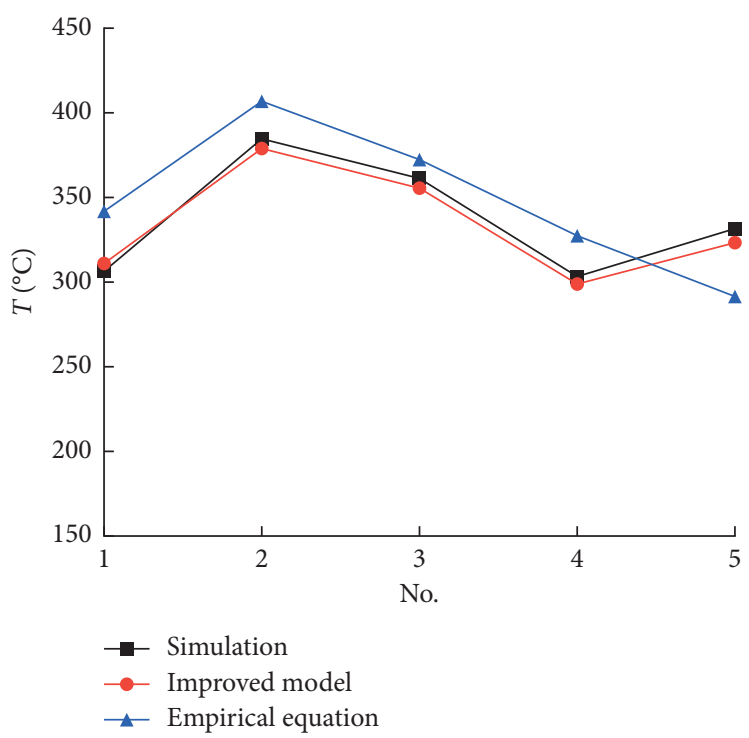

Figure 8: The results of simulation verification.

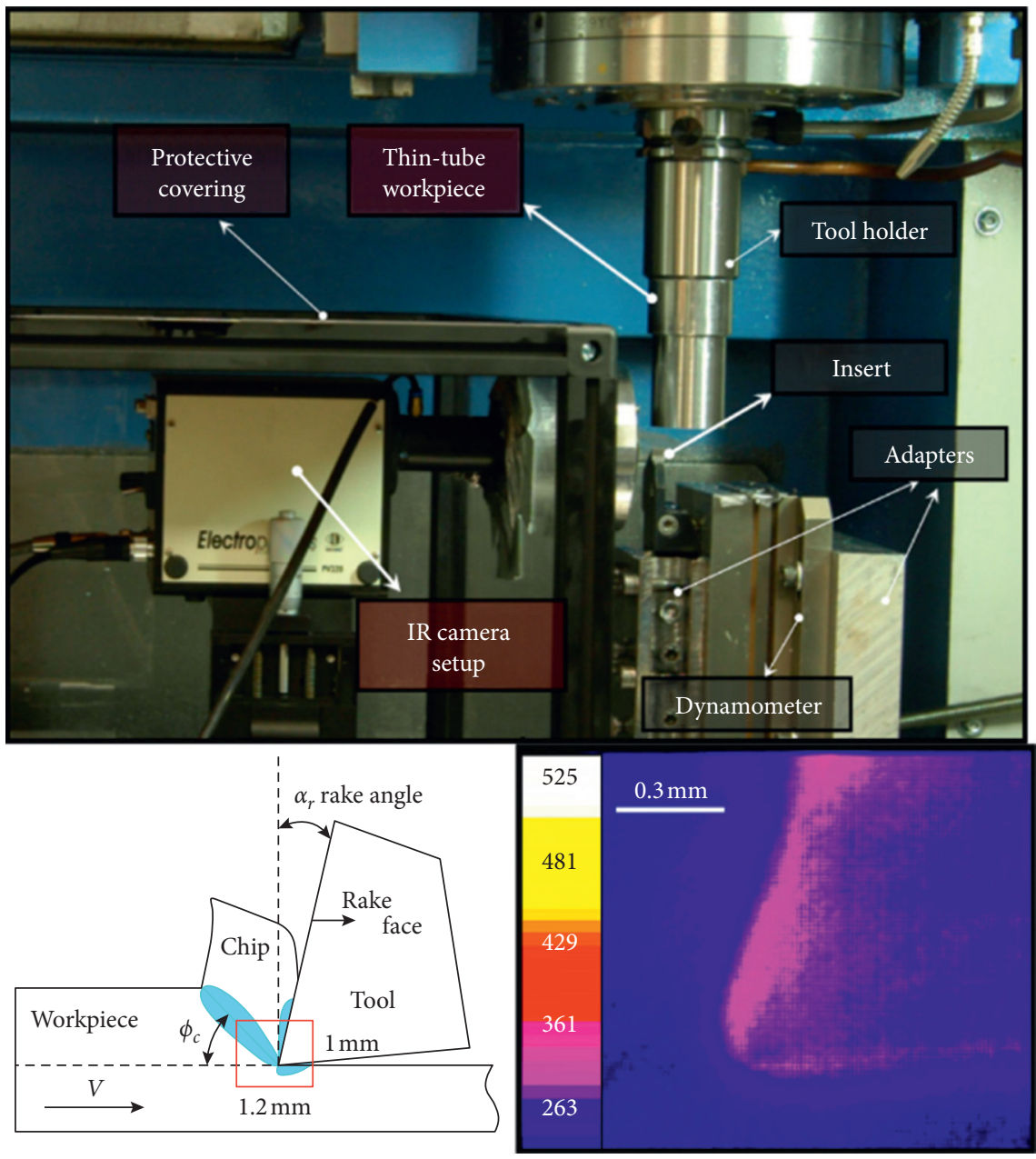

Figure 9: The infrared camera system was integrated with the CNC machine tool for thermal model validation tests. 
TABLE 5: Test conditions and error.

\begin{tabular}{|c|c|c|c|c|c|c|c|c|}
\hline & \multicolumn{8}{|c|}{ No. } \\
\hline & 1 & 2 & 3 & 4 & 5 & 6 & 7 & 8 \\
\hline Rake angle $\left({ }^{\circ}\right)$ & 6 & 6 & 6 & 6 & 18 & 18 & 18 & 18 \\
\hline Feed rate $(\mathrm{mm} / z)$ & 0.05 & 0.1 & 0.15 & 0.2 & 0.05 & 0.1 & 0.15 & 0.2 \\
\hline Error of improved model (\%) & 9.51 & 6.85 & 6.67 & 4.44 & 5.28 & 4.07 & 4.40 & 10.51 \\
\hline Error of empirical equation (\%) & 23.34 & 22.71 & 23.91 & 22.31 & 11.48 & 24.9 & 26.73 & 35.25 \\
\hline
\end{tabular}

\section{Simulation Data Verification}

Five sets of parameters are selected for the simulation test, for verifying the prediction accuracy of the mathematical model; the parameter settings are shown in Table 4; the simulation results and the prediction results of the improved model and empirical equation are shown in Figure 8 . The prediction errors of the improved model for the simulation temperature are $1.28 \%, 1.36 \%, 1.57 \%, 1.34 \%$, and $2.44 \%$, and the prediction errors of the empirical equation for the five simulation temperatures are $11.43 \%$, $5.84, \%, 3.11 \%, 8.71 \%$, and $12.02 \%$. The prediction accuracy of the empirical equation fluctuates sharply because the tool geometry parameters are not considered. According to the previous single-factor analysis, the geometry parameters of the tool have a significant influence on the cutting temperature. When the geometry parameters of the tool change, the cutting temperature changes as well, but the empirical equation cannot reflect this phenomenon, resulting in poor prediction accuracy. In contrast, the improved model has a high prediction accuracy because it takes the relationships between all tool geometry parameters and the cutting temperature into consideration.

\section{Experimental Data Verification}

The orthogonal machining tests with an infrared (IR) camera system were used to verify the improved model. The material is aluminum alloy 7050, and the tool is WC tool.

The infrared camera (Figure 9) used in the experiments has an uncooled focal plane array (FPA) detector. The IR camera has the spectral responsivity of $7-14 \mathrm{~mm}$, an interlace scanning property of $2: 1$, and a minimum resolvable temperature difference of approximately $0.2^{\circ} \mathrm{C}$ at $25^{\circ} \mathrm{C}[33]$.

The cutting parameters are set as follows: spindle speed is $8000 \mathrm{r} / \mathrm{min}$, axial depth is $2 \mathrm{~mm}$, the radial depth of cut is $16 \mathrm{~mm}$, tool diameter is $16 \mathrm{~mm}$, blunt radius is $0.01 \mathrm{~mm}$, and helix angle is $30^{\circ}$. Test with various rake angles and feed rates. The test conditions are shown in Table 5.

Figure 10 shows the prediction of the experimental data by the improved model of cutting temperature and the empirical model of cutting temperature. The prediction errors of the two models for the experimental temperature are shown in Table 5. The results show that the improved model proposed in this paper has a higher prediction accuracy compared with the traditional empirical model.

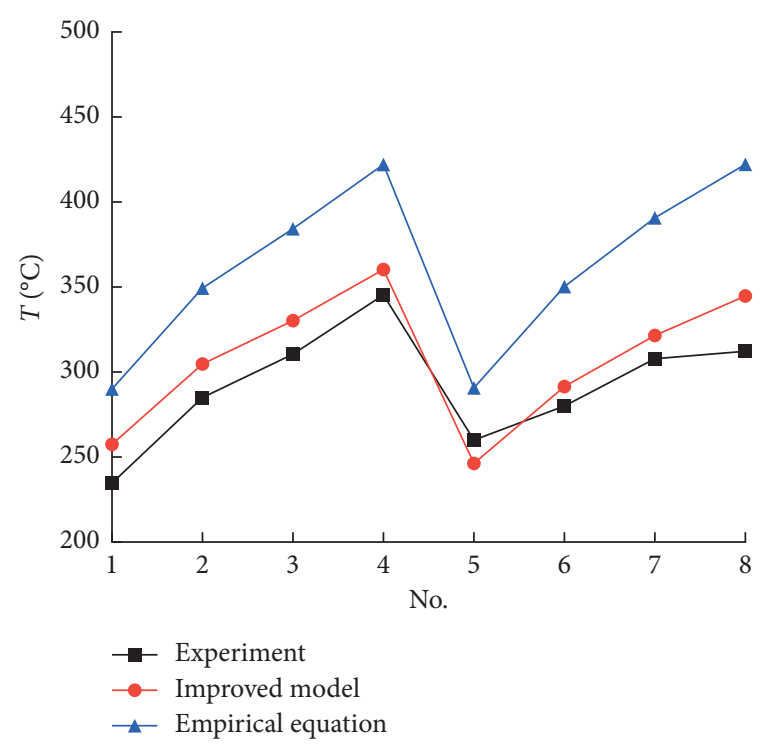

FIgURE 10: The results of experimental verification.

\section{Conclusion}

In the process of Al7050 with cemented carbide tools, the influences of tool geometry parameters on the cutting temperature were studied, and the corresponding mathematical relationship was established for each parameter. The relief angle has little effect on the cutting temperature, and there is a polynomial relationship between the geometry parameters and the cutting temperature.

An improved mathematical model of cutting temperature, which involves tool geometry parameters and milling parameters, is established based on the empirical equation. We can use this model to estimate the cutting temperature of the tool under different tool geometric parameters and milling parameters. For excessively high cutting temperature, the model can well reflect the optimization direction of variables. According to the prediction temperature, we can also change cutting condition, such as the consumption of cutting fluid, to lower cutting temperature, which can prolong tool life and improve machining quality.

The simulation data and experimental data show that the cutting temperature model considering the tool geometric parameters has better prediction accuracy. The average prediction error is $1.6 \%$ for simulation temperature and the average prediction error is $8.6 \%$ for actual cutting temperature. This modeling idea can be used with other types of tools and cutting materials. 


\section{Data Availability}

The relevant data of calculation used to support the findings of this study are included within the article.

\section{Conflicts of Interest}

The authors declare that they have no conflicts of interest regarding the publication of this paper.

\section{Acknowledgments}

This work was supported by the National Natural Science Foundation of China (no. 51605337) and the Zhejiang Provincial Natural Science Foundation of China (no. LQ19E050010).

\section{References}

[1] S. Wojciechowski, T. Chwalczuk, P. Twardowski, and G. M. Krolczyk, "Modeling of cutter displacements during ball end milling of inclined surfaces," Archives of Civil and Mechanical Engineering, vol. 15, no. 4, pp. 798-805, 2015.

[2] S. Wojciechowski, R. W. Maruda, S. Barrans, P. Nieslony, and G. M. Krolczyk, "Optimisation of machining parameters during ball end milling of hardened steel with various surface inclinations," Measurement, vol. 111, pp. 18-28, 2017.

[3] Q. Deng, R. Mo, Z. C. Chen, and Z. Chang, "An analytical approach to cutter edge temperature prediction in milling and its application to trochoidal milling," Applied Sciences, vol. 10, no. 5, pp. 1746-1766, 2020.

[4] S. Yang, S. Su, X. Liu, and P. Han, "Study on milling temperature of titanium alloy with micro-textured ball end milling cutter under radius of blunt edge," Applied Sciences, vol. 10, no. 2, pp. 587-603, 2020.

[5] K. Kadirgama, M. M. Noor, M. M. Rahman, W. Harun, and C. Haron, "Finite element analysis and statistical method to determine temperature distribution on cutting tool in endmilling," European Journal of Scientific Research, vol. 30, no. 3, pp. 451-463, 2009.

[6] L. Yi-jian, Z. Jian-ming, and W. Shu-qing, "Parameter estimation of cutting tool temperature nonlinear model using PSO algorithm," Journal of Zhejiang University-Science A, vol. 6, no. 10, pp. 1026-1029, 2005.

[7] W. J. Bai, Y. L. Ke, H. B. Wu, and H. Y. Dong, "Experimental studies of cutting temperature during high-speed milling of aerospace aluminum," Key Engineering Materials, vol. 394, pp. 719-723, 2009.

[8] B. Fnides, M. A. Yallese, and H. Aouici, "Hard turning of hot work steel AISI H11: evaluation of cutting pressures, resulting force and temperature," Mechanika, vol. 72, no. 4, pp. 59-63, 2008.

[9] D. J. Richardson, M. A. Keavey, and F. Dailami, "Modelling of cutting induced workpiece temperatures for dry milling," International Journal of Machine Tools and Manufacture, vol. 46, no. 10, pp. 1139-1145, 2006.

[10] C. K. Toh, "Comparison of chip surface temperature between up and down milling orientations in high speed rough milling of hardened steel," Journal of Materials Processing Technology, vol. 167, no. 1, pp. 110-118, 2005.

[11] P. Spânu and M. Iliescu, "Mathematical model of temperature in milling glass fiber reinforced polymeric composites," UPB Scientific Bulletin, Series, vol. 70, no. 1, pp. 63-72, 2008.
[12] S. E. M. Chien, M. M. Reddy, V. C. C. Lee, and D. Sujan, "The study of coated carbide ball end milling tools on Inconel 718 using numerical simulation analysis to attain cutting force and temperature predictive models at the cutting zone," Materials Science Forum, vol. 882, pp. 28-35, 2017.

[13] L. B. Abhang and M. Hameedullah, "Chip-tool interface temperature prediction model for turning process," International Journal of Engineering Science \& Technology, vol. 2, no. 4, pp. 382-393, 2010.

[14] H. Saglam, S. Yaldiz, and F. Unsacar, "The effect of tool geometry and cutting speed on main cutting force and tool tip temperature," Materials \& Design, vol. 28, no. 1, pp. 101-111, 2007.

[15] M. Santhanakrishnan, P. S. Sivasakthivel, and R. Sudhakaran, "Modeling of geometrical and machining parameters on temperature rise while machining Al 6351 using response surface methodology and genetic algorithm," Journal of the Brazilian Society of Mechanical Sciences and Engineering, vol. 39, no. 2, pp. 487-496, 2015.

[16] J. Sheng, Y. J. Chiu, and B. J. Lin, "Determination of a coupling equation for milling parameters based on optimal cutting temperature," The International Journal of Advanced Manufacturing Technology, vol. 98, no. 1-4, pp. 129-141, 2017.

[17] V. S. Kaushik, M. Subramanian, and M. Sakthivel, "Optimization of processes parameters on temperature rise in CNC end milling of Al 7068 using hybrid techniques," Materials Today: Proceedings, vol. 5, no. 2, pp. 7037-7046, 2018.

[18] A. Rana and N. Kumar, "Experimental investigation of temperature in turning operation of EN 19 Steel," SSRN Electronic Journal, vol. 2018, Article ID 3290409, 2018.

[19] N. b. Zeelanbasha, V. Senthil, and B. R. Senthil Kumar, "An integrated approach of RSM and MOGA for the prediction of temperature rise and surface roughness in the end milling of Al 6061-T6," Transactions of Famena, vol. 42, no. 3, pp. 115-128, 2018.

[20] Y. Zheng, P. Wang, N. Liu, and M. Wang, "Simulation research on parameters optimization of 7075 aluminum alloy milling," Machinery Design \& Manufacture, vol. 351, no. 5, pp. 171-174, 2020.

[21] Z. Ping, X. Yue, H. Shuangfeng, S. Ailing, L. Baoshun, and Y. Xiao, "Experiment and simulation on the high-speed milling mechanism of aluminum alloy 7050-T7451," Vacuum, vol. 182, Article ID 109778, 2020.

[22] F. M. Aneiro, R. T. Coelho, and L. C. Brandão, "Turning hardened steel using coated carbide at high cutting speeds," Journal of the Brazilian Society of Mechanical Sciences and Engineering, vol. 30, no. 2, pp. 104-109, 2008.

[23] X. Cui, J. Zhao, and Z. Pei, "Analysis of transient average tool temperatures in face milling," International Communications in Heat and Mass Transfer, vol. 39, no. 6, pp. 786-791, 2012.

[24] R. Zhou, "Analytical model of workpiece surface temperature prediction in 4-axis milling process," The International Journal of Advanced Manufacturing Technology, vol. 111, no. 7-8, pp. 2155-2162, 2020.

[25] S. Lin, F. Peng, J. Wen, Y. Liu, and R. Yan, "An investigation of workpiece temperature variation in end milling considering flank rubbing effect," International Journal of Machine Tools and Manufacture, vol. 73, pp. 71-86, 2013.

[26] D. Sreeramulu, C. J. Rao, Y. Sagar, and M. Venkatesh, "Finite element modeling and machining of $\mathrm{Al} 7075$ using coated cutting tools," Materials Today: Proceedings, vol. 5, no. 2, pp. 8364-8373, 2018.

[27] L. N. L. d. Lacalle, A. Celaya, A. Lamikiz, and U. Bravo, "Effect of coatings and tool geometry on the dry milling of wrought 
aluminium alloys," International Journal of Materials and Product Technology, vol. 32, no. 1, pp. 41-55, 2008.

[28] J. K. Rai, L. Villedieu, and P. Xirouchakis, "Mill-cut: a neural network system for the prediction of thermo-mechanical loads induced in end-milling operations," The International Journal of Advanced Manufacturing Technology, vol. 37, no. 34, pp. 256-264, 2007.

[29] I. Korkut, A. Acır, and M. Boy, "Application of regression and artificial neural network analysis in modelling of tool-chip interface temperature in machining," Expert Systems with Applications, vol. 38, no. 9, pp. 11651-11656, 2011.

[30] S. Masoudi, M. Sima, and M. Tolouei-Rad, "Comparative study of ann and anfis models for predicting temperature in machining," Journal of Engineering Science and Technology, vol. 13, no. 1, pp. 211-225, 2018.

[31] X. Zhang, J. Zhang, H. Zhou, Y. Ren, and M. Xu, "A novel milling force model based on the influence of tool geometric parameters in end milling," Advances in Mechanical Engineering, vol. 10, no. 9, pp. 1-9, 2018.

[32] V. P. Astakhov, Metal Cutting Mechanics, CRC Press, Boca Raton, FL, USA, 1998.

[33] I. Lazoglu and B. Bugdayci, "Thermal modelling of end milling," CIRP Annals, vol. 63, no. 1, pp. 113-116, 2014. 